\title{
A Comparative Study on the Therapeutic Effect of en Bloc Transurethral Resection of Bladder Tumors with Needle Electrode and Traditional Transurethral Resection of Bladder Tumor on Non-Muscle Invasive Bladder Tumor
}

Jiashuo Li

Lanzhou University Second Hospital

Panfeng Shang ( $\nabla$ lijsh18@lzu.edu.cn )

Second Hospital of Lanzhou University

Yidi He

Lanzhou University Second Hospital

Yichao Shang

Lanzhou University Second Hospital

\section{Xu Zheng}

Lanzhou University Second Hospital

Research article

Keywords: Bladder cancer, needle electrode, En bloc transurethral resection

Posted Date: December 23rd, 2020

DOI: https://doi.org/10.21203/rs.3.rs-131552/v1

License: (c) (1) This work is licensed under a Creative Commons Attribution 4.0 International License.

Read Full License 


\section{Abstract}

\section{Background:}

En bloc transurethral resection of bladder tumors (ERBT) as an improved method of traditional transurethral resection of bladder tumor (TURBT), has not been standardized. The purpose of this study is to evaluate the safety and effectiveness of the technology.

\section{Methods:}

We divide non-muscle invasive bladder cancer into an experimental group receiving ERBT and a control group receiving traditional TURBT, and compared the recurrence rate by Kaplan-Meier curve adjusted by propensity score matching (PSM) analysis. In addition, we analyzed the independent risk factors affecting the recurrence rate of NMBIC by COX risk regression.

\section{Discussion:}

Compared with traditional transurethral resection of bladder tumor treatment, En bloc transurethral resection of bladder tumors has less intraoperative bleeding and high surgical safety. Moreover, this technique can obtain high-quality pathological specimens, which has obvious advantages in postoperative pathological assessment.

\section{Background}

As a common urological disease, bladder cancer is clinically guided by TNM staging. T1, Ta and carcinoma in situ are usually called non-muscle invasive bladder cancer (NMIBC). For NMIBC, current treatment aims to preserve bladder function and remove all tumor tissue $\mathrm{e}^{1-2}$. The preferred treatment is transurethral resection of bladder tumor (TURBT), which is both a treatment method and a diagnostic method. Studies have shown that $70 \%-80 \%$ of patients are judged as NMIBC in the first diagnosis ${ }^{1-2}$. At the same time, after proper treatment of NMIBC patients, the recurrence rate within 5 years after surgery is $15-61 \%$, and $1-45 \%$ will occur disease progression ${ }^{3}$.

However, TURBT has certain defects, including thermal damage of adjacent tissues and fragmentation of tumor tissue, which reduces the accuracy of pathological assessment and increases the risk of recurrence ${ }^{4}$. In order to overcome the shortcomings of traditional TURBT treatment, Japanese scholars first proposed the en bloc transurethral resection of bladder tumors (ERBT) to treat NMIBC in 1980. The report believes that this procedure can overcome the main defects of traditional TURBT ${ }^{5}$. ERBT is usually excised around the base of the tumor, and obvious healthy tissue is reserved around the tumor as a preventive margin. Gradually advance to the bottom of the tumor, reaching the bladder muscle layer.

However, because ERBT has not been standardized, most practitioners still prefer to use traditional TURBT to treat patients with NMIBC. Therefore, we designed this experiment. The clinical data and 
follow-up data of patients with NMIBC treated in our department from February 2016 to February 2020 were collected. The patients who received ERBT were included in the experimental group, and the patients who received TURBT were included in the control group. The treatment effect and recurrence rate of the two groups were compared to evaluate the technical safety and effectiveness.

\section{Method}

\section{Patients enrollment}

From February 2016 to February 2020, clinical data of 212 patients with NMIBC who received bladder cancer treatment in the Department of Urology, Lanzhou University.

Inclusion criteria: 1) undergoing transurethral resection of bladder tumor; 2) non-muscle invasive bladder cancer (Ta-T1NOM0); pathological diagnosis of urothelial carcinoma; 3) no distant metastasis; 4) complete clinical data ; 5) No other urinary malignant tumor diseases.

Exclusion criteria: 1) The tumor has invaded the ureter, prostate, and urethra; 2) Postoperative diagnosis of muscle invasive bladder cancer and above; 3 ) History of chemotherapy before surgery.

In the end, a total of 212 patients who met the criteria were included in this study, including 39 in the experimental group and 173 in the control group.

\section{Treatment}

Experimental group: The patient was placed in lithotomy position after anesthesia, the irrigating solution was saline, the surgical area was disinfected, and sterile cloth were placed. Visually place the resectoscope into the bladder to determine the number, size and location of the tumor. First mark a circle with a needle electrode at the normal mucosa of 0.5 to $1 \mathrm{~cm}$ around the root of the tumor, and then electrocut the mucosa to the bladder muscle layer, surround the root of the tumor, and completely cut the tumor. The hemorrhage was stopped by electrocoagulation mode. If the tumor is small, it is flushed out with a irrigator. When it is difficult to flush out, it is taken out with gripping pliers. When the tumor is too large, divide the tumor body 2-3 times before rushing out of the tunnel. Finally, a part of the tissue was taken from the wound surface as a base specimen. F22 three-lumen urinary catheter was placed after operation.

Control group: The patient was placed in lithotomy position after anesthesia, the irrigating solution was saline, the surgical area was disinfected, and sterile cloth were placed. Visually place the resectoscope into the bladder to determine the number, size and location of the tumor. Use a spade electrode to remove the tumor layer by layer, cut to the muscular layer. The hemorrhage was stopped by electrocoagulation mode. Finally, a part of the tissue was taken from the wound surface as a base specimen. Use the 
irrigator to flush out the tumor tissue fragments, and leave the specimens for examination. F22 threelumen urinary catheter was placed after operation.

Postoperative bladder infusion: All patients undergo bladder instillation after operation. Infusion drugs include cytotoxic drugs and immunologic agents. Cytotoxic drugs include epirubicin, pirarubicin, gemcitabine, etc.; individual patients choose immunologic agents, such as BCG. Method: Once a week (9 times). Treatment: Initially once a week (10 times), then once a month (10 times).

\section{Data collection}

By reading the patient's medical records, we collected the following data: the patient's baseline treatment (age, sex, time of surgery), tumor characteristics (tumor size, tumor site, number of tumors), surgical data (operative time, intraoperative blood loss, surgical complications), postoperative conditions (ventilation time, bladder flushing time, urinary catheter time), clinical TNM staging (2009 TNM staging ${ }^{6}$ ), pathological grading (WHO 2004 grading $^{7}$ ). The primary endpoint of this study was tumor recurrence, which was calculated from the time of patient received treatment to the time of re-diagnosis that the tumor recurred or reached the final follow-up time.

\section{Statistical analysis}

Pearson $\chi 2$ or Fisher exact test (for categorical data) and independent sample $t$ test (for continuous variables) were used to evaluate the association between treatment methods and patient characteristics and clinical characteristics. In order to reduce the bias of non-random treatment allocation, we used the propensity score matching (PSM) method. All baseline covariates were considered, including age, gender, tumor size, tumor number, pathological grade, tumor stage, receiving repeat TURBT, and year of diagnosis. For PSM, ERBT-treated patients were matched 1:1 with traditional TURBT-treated patients with a propensity score of 0.05 calipers.

In this model, Kaplan-Meier curves are used to calculate the overall recurrence rate. Univariate and multivariate Cox models were conducted to compare groups in PSM analysis. P value $<0.05$ was considered statistically significant. Statistical analysis was performed using Statistical Product for Social Sciences (SPSS) software (version 24.0).

\section{Result}

\section{Patients' characteristics}

From 2016 to 2020, a total of 212 patients with NMIBC were included in the study, of which 39 patients received ERBT and 173 patients received traditional TURBT. The patient's baseline data is shown in Table 1. As shown in Table 1, before the PSM match, there is a significant difference between the two 
groups in receiving repeat TURBT. After PSM matching, there were no significant differences between the two groups of factors.

\section{Survival analysis}

The median follow-up time for the entire study was 21 months (2-51 months). In this study, the total recurrence rates of the experimental group and the control group were $15.4 \%$ and $23.7 \%(P=0.592)$, respectively. The 6-month recurrence rate was $10.3 \%$ and $8.1 \%$, the 1 -year recurrence rate was $12.8 \%$ and $13.9 \%$, and the 3 -year recurrence rate was $15.4 \%$ and $22.0 \%$, respectively. (Fig. $1 \mathrm{~A}$, Table 2). The results of multivariate analysis showed that pathological grade, tumor size, and tumor number were independent risk factors affecting patients' recurrence (Table 3). In the head-to-head PSM analysis, 33 patients receiving ERBT treatment and 33 patients receiving traditional TURBT treatment were successfully matched, and the age, gender, tumor size, tumor number, pathological grade, tumor stage, receiving repeat TURBT were balanced between the two groups (Table 1). multivariate analysis results are shown in Table 4. The total recurrence rates of the experimental group and the control group were $18.2 \%$ and $24.2 \%$, respectively $(P=0.226)$. The 6 -month recurrence rate was $12.1 \%$ and $15.2 \%$, the 1 -year recurrence rate was $15.2 \%$ and $18.2 \%$, and the 3 -year recurrence rate was $18.2 \%$ and $24.2 \%$, respectively. (Fig. $1 \mathrm{~B}$, Table 2). 
Table 1

Patient baseline data

\begin{tabular}{|c|c|c|c|c|c|c|}
\hline \multirow[t]{2}{*}{ Variables } & \multicolumn{2}{|c|}{ Before PSM $(n=212)$} & \multirow[t]{2}{*}{$P$ value } & \multicolumn{2}{|c|}{ After PSM $(n=66)$} & \multirow{2}{*}{$\begin{array}{l}\mathrm{P} \\
\text { value }\end{array}$} \\
\hline & $\begin{array}{l}\text { ERBT }(n= \\
39)\end{array}$ & $\begin{array}{l}\text { TURBT }(n= \\
173)\end{array}$ & & $\begin{array}{l}\text { ERBT }(n= \\
33)\end{array}$ & $\begin{array}{l}\text { TURBT }(n= \\
\text { 33) }\end{array}$ & \\
\hline Sex & & & 0.904 & & & 0.523 \\
\hline male & 31 & 136 & & 26 & 28 & \\
\hline female & 8 & 37 & & 7 & 5 & \\
\hline Age & & & 0.452 & & & 0.398 \\
\hline$<70$ & 29 & 118 & & 23 & 26 & \\
\hline$\geq 70$ & 10 & 55 & & 10 & 7 & \\
\hline Grade & & & 0.817 & & & 0.125 \\
\hline low & 30 & 136 & & 24 & 18 & \\
\hline High & 9 & 37 & & 9 & 15 & \\
\hline Stage & & & 0.880 & & & 0.720 \\
\hline Ta & 9 & 38 & & 5 & 4 & \\
\hline T1 & 30 & 135 & & 28 & 29 & \\
\hline Tumor size & & & 0.688 & & & 0.769 \\
\hline$<3 \mathrm{~cm}$ & 32 & 137 & & 26 & 25 & \\
\hline$\geq 3 \mathrm{~cm}$ & 7 & 36 & & 7 & 8 & \\
\hline $\begin{array}{l}\text { Number of } \\
\text { tumors }\end{array}$ & & & 0.571 & & & 0.592 \\
\hline single & 25 & 119 & & 22 & 24 & \\
\hline multiple & 14 & 54 & & 11 & 9 & \\
\hline Repeat TURBT & & & 0.000001 & & & 1 \\
\hline received & 11 & 7 & & 5 & 5 & \\
\hline no received & 28 & 166 & & 28 & 28 & \\
\hline Detrusor & & & 0.056 & & & 0.076 \\
\hline yes & 39 & 158 & & 33 & 30 & \\
\hline no & 0 & 15 & & 0 & 3 & \\
\hline
\end{tabular}


Table 2

Recurrence rate

\begin{tabular}{|lllll|}
\hline \multirow{2}{*}{ Time } & \multicolumn{2}{l}{ Unmatched(\%) } & \multicolumn{2}{l|}{ PSM(\%) } \\
\cline { 2 - 5 } & ERBT & TURBT & ERBT & TURBT \\
\hline $\begin{array}{l}\text { 6- } \\
\text { month }\end{array}$ & $10.3 \%$ & $8.1 \%$ & $12.1 \%$ & $15.2 \%$ \\
\hline 1-year & $12.8 \%$ & $13.9 \%$ & $15.2 \%$ & $18.2 \%$ \\
\hline 2-year & $15.4 \%$ & $20.8 \%$ & $18.2 \%$ & $24.2 \%$ \\
\hline 3-year & $15.4 \%$ & $22.0 \%$ & $18.2 \%$ & $24.2 \%$ \\
\hline 4-year & $15.4 \%$ & $23.7 \%$ & $18.2 \%$ & $24.2 \%$ \\
\hline
\end{tabular}

Table 3

Univariate and multivariate analysis of survival before PSM analysis

\begin{tabular}{|c|c|c|c|c|c|c|}
\hline \multirow[t]{2}{*}{ Variables } & \multicolumn{2}{|c|}{ Univariate analysis } & \multirow[t]{2}{*}{$P$ value } & \multicolumn{2}{|c|}{ Multivariate analysis } & \multirow[t]{2}{*}{$P$ value } \\
\hline & HR & $95 \% \mathrm{Cl}$ & & HR & $95 \% \mathrm{Cl}$ & \\
\hline $\begin{array}{l}\text { Sex } \\
\text { (male) }\end{array}$ & 2.398 & $0.949-6.063$ & 0.065 & & & \\
\hline $\begin{array}{l}\text { Age } \\
(<70)\end{array}$ & 0.807 & $0.441-1.476$ & 0.485 & & & \\
\hline $\begin{array}{l}\text { Grade } \\
\text { (low) }\end{array}$ & 0.348 & $0.191-0.635$ & 0.001 & 0.396 & $0.216-0.726$ & 0.003 \\
\hline $\begin{array}{l}\text { Stage } \\
(\mathrm{T} 1)\end{array}$ & 2.125 & $0.902-5.008$ & 0.085 & & & \\
\hline $\begin{array}{l}\text { Tumor size } \\
(<3 \mathrm{~cm})\end{array}$ & 2.563 & $1.407-4.668$ & 0.002 & 0.472 & $0.257-0.868$ & 0.016 \\
\hline $\begin{array}{l}\text { Number of tumors } \\
\text { (multiple) }\end{array}$ & 0.475 & $0.268-0.841$ & 0.011 & 0.547 & $0.307-0.975$ & 0.041 \\
\hline $\begin{array}{l}\text { Repeat TURBT } \\
\text { (no received) }\end{array}$ & 3.888 & $0.534-28.292$ & 0.18 & & & \\
\hline
\end{tabular}


Table 4

Univariate and multivariate analysis of survival in PSM analysis

\begin{tabular}{|c|c|c|c|c|c|c|}
\hline \multirow[t]{2}{*}{ Variables } & \multicolumn{2}{|c|}{ Univariate analysis } & \multirow[t]{2}{*}{$P$ value } & \multicolumn{2}{|c|}{ Multivariate analysis } & \multirow[t]{2}{*}{$P$ value } \\
\hline & HR & $95 \% \mathrm{Cl}$ & & HR & $95 \% \mathrm{Cl}$ & \\
\hline $\begin{array}{l}\text { Sex } \\
\text { (male) }\end{array}$ & 1.445 & $0.323-6.459$ & 0.630 & & & \\
\hline $\begin{array}{l}\text { Age } \\
(<70)\end{array}$ & 0.777 & $0.243-2.480$ & 0.670 & & & \\
\hline $\begin{array}{l}\text { Grade } \\
\text { (low) }\end{array}$ & 0.206 & $0.067-0.634$ & 0.006 & 0.294 & $0.092-0.944$ & 0.040 \\
\hline $\begin{array}{l}\text { Stage } \\
(\mathrm{T} 1)\end{array}$ & 3.102 & $0.402-23.940$ & 0.278 & & & \\
\hline $\begin{array}{l}\text { Tumor size } \\
(<3 \mathrm{~cm})\end{array}$ & 0.172 & $0.059-0.502$ & 0.001 & 0.236 & $0.078-0.716$ & 0.011 \\
\hline $\begin{array}{l}\text { Number of tumors } \\
\text { (multiple) }\end{array}$ & 0.744 & $0.249-2.222$ & 0.596 & & & \\
\hline $\begin{array}{l}\text { Repeat TURBT } \\
\text { (no received) }\end{array}$ & 2.319 & $0.302-17.776$ & 0.418 & & & \\
\hline
\end{tabular}

\section{Disease progression}

Of the 212 patients, 15 patients had disease progression (clinical stage or pathological grade progression). Among them, 1 case was in the experimental group and 14 cases were in the control group. The progress rates were $2.6 \%$ and $8.1 \%$, respectively $(P=0.224)$. After PSM matching, the progress rates of the two groups were $3.0 \%$ and $9.1 \%(P=0.302)$. At the same time, for high-grade tumors, the progression rates of the two groups before PSM were $11.1 \%$ and $10.8 \%(P=0.979)$, and the progression rates of the two groups after PSM were $11.1 \%$ and $13.3 \%(P=0.873)$. As shown in Table 5. 
Table 5

Disease progression

\begin{tabular}{|lllllllll|}
\hline & Before PSM & & $X^{2}$ & P value & After PSM & $X^{2}$ & P value \\
\hline & ERBT & TURBT & & & ERBT & TURBT & \\
\hline Total & 39 & 173 & & & 33 & 33 & & \\
\hline Progress & 1 & 14 & & & 1 & 3 & & \\
\hline Rate & $2.6 \%$ & $8.1 \%$ & 1.479 & 0.224 & $3.0 \%$ & $9.1 \%$ & 1.065 & 0.302 \\
\hline High grade & 9 & 37 & & & 9 & 15 & & \\
\hline Progress & 1 & 4 & & & 1 & 2 & & \\
\hline Rate & $11.1 \%$ & $10.8 \%$ & 0.001 & 0.979 & $11.1 \%$ & $13.3 \%$ & 0.025 & 0.873 \\
\hline
\end{tabular}

\section{Comparison of perioperative conditions}

This study collected perioperative data of 212 patients, including operation time, intraoperative hemorrhage, intraoperative complications, postoperative fart time, bladder irrigation time, and catheterization time (Table 6). As shown in the table, the two groups differed in intraoperative blood loss and catheterization time. After PSM matching, the two groups only had statistical differences in intraoperative bleeding $(P=0.04)$. 
Table 6

Perioperative conditions

\begin{tabular}{|c|c|c|c|c|c|c|}
\hline Variables & $\begin{array}{l}\text { Before } \\
\text { PSM }\end{array}$ & & $\begin{array}{l}P \\
\text { value }\end{array}$ & $\begin{array}{l}\text { After } \\
\text { PSM }\end{array}$ & & $\begin{array}{l}P \\
\text { value }\end{array}$ \\
\hline & ERBT & TURBT & & ERBT & TURBT & \\
\hline operation time (min) & $\begin{array}{l}50.2 \pm \\
20.3\end{array}$ & $\begin{array}{l}40.5 \pm \\
19.8\end{array}$ & 0.185 & $\begin{array}{l}48.8 \pm \\
21.8\end{array}$ & $\begin{array}{l}59.0 \pm \\
22.9\end{array}$ & 0.067 \\
\hline $\begin{array}{l}\text { intraoperative } \\
\text { hemorrhage(ml) }\end{array}$ & $12.7 \pm 9.0$ & $19.0 \pm 7.7$ & $<0.01$ & $12.6 \pm 9.4$ & $16.7 \pm 6.2$ & 0.04 \\
\hline $\begin{array}{l}\text { intraoperative } \\
\text { complications }\end{array}$ & $5.1 \%$ & $1.2 \%$ & 0.1 & & & \\
\hline Bladder perforation & 0 & 0 & & & & \\
\hline obturator reflex & 2 & 2 & & & & \\
\hline $\begin{array}{l}\text { postoperative fart } \\
\text { time(day) }\end{array}$ & $1.9 \pm 0.3$ & $1.8 \pm 0.4$ & 0.547 & $1.9 \pm 0.3$ & $1.8 \pm 0.4$ & 0.5 \\
\hline bladder irrigation time(day) & $2.3 \pm 0.4$ & $2.2 \pm 0.5$ & 0.686 & $2.2 \pm 0.4$ & $2.4 \pm 0.8$ & 0.44 \\
\hline catheterization time(day) & $4.9 \pm 1.8$ & $3.7 \pm 1.4$ & $<0.01$ & $4.8 \pm 1.8$ & $4.0 \pm 1.7$ & 0.097 \\
\hline
\end{tabular}

\section{Postoperative pathology results}

In this study, 212 patients were diagnosed with non-muscle invasive urothelial carcinoma, 166 cases of low grade (30 cases in the experimental group, 136 cases in the control group), 46 cases of high grade tumors ( 9 cases in the experimental group, 37 cases in the control group). The detrusor muscle tissue was found in the postoperative pathology of all patients in the experimental group. In the control group, 15 patients were not found to have detrusor muscles (8.6\%). After PSM matching, 3 patients in the control group had no detrusor muscles $(9.1 \%)$ in their postoperative pathological tissues. Moreover, the edge of the pathological tissue in the experimental group was clear and there were few burn marks, while the edge of the pathological tissue in the control group showed more serious burn marks.

\section{Discussion}

The incidence of bladder cancer is increasing year by year, and surgery is its main treatment strategy. Until today, ERBT technology has been widely accepted by clinicians. In addition, a variety of ERBT technologies have been invented ${ }^{8-9}$. However, ERBT does not have a definite standard. Moreover, its efficacy with traditional TURBT is also controversial. At present, random comparison of ERBT with needle electrode and traditional TURBT is rare in clinic. 
Our approach based on propensity score matching directly compared the therapeutic benefits of ERBT and traditional TURBT. After 1:1 matching, there was no statistically significant difference in the recurrence rate between the two groups $(P=0.226)$. One study suggested that ERBT can avoid tumor fragmentation, thereby minimize the floating of tumor cells, reducing the risk of recurrence of tumors ${ }^{4}$. However, we did not find that ERBT showed an advantage in terms of recurrence rate and progression rate. This is consistent with the results of some literature published in recent years. Zhang et $\mathrm{al}^{10}$ compared 90 patients with NMIBC treated by transurethral resection of bladder tumors (40 in the ERBT group and 50 in the traditional TURBT group), and found that there was no difference in the total recurrence rate between the two groups $(20 \%$ vs $24 \%, P=0.650)$. In addition, a study ${ }^{11}$ compared ERBT with 1.9 microm vela laser and traditional TURBT, and there was no difference in recurrence rate between the two groups $(P>0.05)$. However, an randomized controlled trial ${ }^{12}$ believes that although the recurrence rate at the same location is similar in the ERBT group and the TURBT group ( $4.9 \%$ vs $7.5 \%, P>0.05)$, the ERBT group has a clear advantage in terms of overall recurrence rate ( $17.1 \%$ vs $27.5 \%, \mathrm{P}<0.05)$. Therefore, in terms of recurrence rate, whether ERBT can achieve better efficacy than the traditional TURBT group requires more experiments to prove. In terms of progression rate, this study found that although the results of the two groups were not statistically different, when the factor of tumor grade was limited, the difference in progression rate between the two groups was significantly reduced. It can be seen that tumor grade seems to be a factor affecting tumor progression.

In terms of surgical effect, we compared the effects of two different surgical methods on operation time, intraoperative hemorrhage, intraoperative complications, postoperative fart time, bladder irrigation time, and catheterization time, etc. The results showed that the ERBT group had an advantage in intraoperative bleeding compared with the traditional TURBT group $(P=0.04)$. We believe that during the ERBT operation, the tumor is usually removed from the surrounding tumor and advanced to the root of the tumor, so that the blood vessels around the tumor can be cut off and hemostasis can be stopped in time, which allows a better visual field during surgery and bleeding Also less. In the study by Balan et al ${ }^{12}$, compared with the traditional TURBT group, the ERBT group had a lower drop in hemoglobin ( $0.28 \mathrm{vs}$ $0.76 \mathrm{~g} / \mathrm{dL}, \mathrm{P}<0.05$ ). It can be seen that ERBT does have an advantage in improving intraoperative bleeding. Some articles reported that ERBT can effectively reduce the time of flushing, catheterization and hospitalization ${ }^{12-14}$, but in our study, no differences were found between the two groups. In terms of surgery time, some studies believe that ERBT takes less time (13.4 vs $19.7 \mathrm{~min}, \mathrm{P}<0.05)^{12}$, and some studies find that ERBT takes longer surgery time (40.0 vs $19.5 \mathrm{~min}, P=0.0002)^{13}$. In our opinion, the operation time is mainly related to the experience of the surgeon doctor and the surgical instruments used. In this study, the surgeon doctor has extensive experience in surgery. At the same time, we use needle electrodes as a resection tool, which has a small contact surface with the tissue, which effectively reduces the time spent adjusting the position. Of course, the small contact area will slow the rate of resection, therefore, we did not find a difference in surgical time between the two groups. After PSM matching, we found that there were no surgical complications in the two groups of patients. Analyzing the data before matching, there was no difference in obturator nerve reflex between the two groups. This 
seems to be contrary to some research results ${ }^{12,15}$. However, reading of the relevant literature carefully reveals that the traditional TURBT energy source in this type of research is a plasma monopolar source, while our traditional TURBT group energy source is a plasma bipolar electrode. In theory, the use of bipolar energy can reduce the risk of obturator nerve reflexes. Avallone et al ${ }^{16}$ compared the safety and efficacy of monopolar and bipolar energy TURBT in the treatment of NMIBC, and found that the use of bipolar energy has a tendency to reduce obturator nerve reflexes (2.6\% vs $5.8 \%)$.

Research suggests that the presence of detrusor muscles is an important surgical quality control indicator used to indicate complete tumor resection ${ }^{17}$. The results of Zhang et al ${ }^{10}$ showed that the presence of detrusor muscle was easier to find in the pathological tissue after ERBT (100\% vs $54 \%, \mathrm{P}<$ 0.01). Another study also recognized the advantages of ERBT in this regard $(2.94 \% \text { vs } 20.0 \%, P=0.04)^{18}$. In this study, we also found that the pathological tissue after ERBT seems to be easier to find the detrusor muscle ( $100 \%$ vs $90.9 \%)$, however, statistical analysis did not find a difference between the two groups. In our analysis, this may be due to the fact that the two surgical procedures in this study both excised the tissue from the surgical wound and left it as the base specimen, which can effectively find the detrusor muscle. Comparing the postoperative pathological results of the two groups, ERBT can obtain higherquality tumor specimens, especially less burn marks on the muscle layer, which is very beneficial for postoperative evaluation of the depth of tumor invasion.

In multivariate analysis, we found that tumor grade and tumor size are risk factors affecting tumor recurrence rate, which may be due to two factors related to postoperative tumor residuals. The EAU guidelines suggest that patients with high-grade bladder cancer have a higher risk of residual tumor after surgery ${ }^{1}$. Yuk et al ${ }^{19}$ analyzed the risk factors affecting the residual tumor after TURBT by univariate and multivariate analysis methods. The results showed that the high-grade tumors (1.925 [1.014-3.656], $\mathrm{P}=$ $0.045)$ and tumors $\geq 3 \mathrm{~cm}(2.56[1.13-6.04], \mathrm{P}=0.026)$ were independent risk factors for tumor residuals.

In this study, when performing ERBT on a large bladder tumor, how to completely remove the tumor is a puzzling thing. Most studies currently use $3 \mathrm{~cm}$ as the upper limit of ERBT. For tumors that are too large, we divide them 2-3 times and then take them out. Studies have suggested that fragmentation of tumor tissue can affect the pathological results of the tumor and underestimate the stage of the tumor. and in the process of tumors cutting, cancer cells are prone to grow and metastasize, which leads to recurrence 4 . Hayashida et al ${ }^{20}$ proposed a new scheme combining endoscopic mucosal resection (EMR) and ERBT. EMR is used to remove the part of the tumor that protrudes from the mucosa, and use ERBT to remove the remaining part. And compare the recurrence rate of this surgical method with traditional TURBT. The results showed that there was no difference in the recurrence rate between the two groups $(P=0.662)$. In addition, the postoperative pathology of the new surgery can determine the degree of infiltration, while $19.4 \%$ of patients in the traditional group cannot determine the degree of infiltration $(P=0.016)$. Therefore, it seems to be a feasible method to segment tumor samples properly.

\section{Conclusion}


En bloc transurethral resection of bladder tumors with needle electrode is used as a treatment method for bladder tumor. Compared with traditional TURBT treatment, it has less intraoperative bleeding and high surgical safety. Moreover, this technique can obtain high-quality pathological specimens, which has obvious advantages in postoperative pathological assessment. In terms of recurrence-free survival, there is no difference between ERBT and traditional TURBT.

\section{Abbreviations}

ERBT $=$ En bloc transurethral resection of bladder tumors

TURBT = transurethral resection of bladder tumor

$\mathrm{NMIBC}=$ non-muscle invasive bladder cancer

PSM= propensity score matching

BCG= Bacillus Calmette-Guerin

\section{Declarations}

\section{Acknowledgements:}

We want to especially acknowledge all the participants in this study

\section{Authors' Contributions:}

Each author has participated sufficiently in the work and takes public responsibility for appropriate portions of the content. The authors have agreed to be accountable for all aspects of the work and ensure that questions related to the accuracy or integrity of any part of the work are appropriately investigated and resolved. JSL is the author of the article and the main collector of data. PFS as the instructor to make appropriate revisions to the article. YDH helps data collection. YCS helps data collection. XZ helps data collection.

\section{Funding:}

Key Science and Technology Foundation of Gansu Province

\section{Availability of data and materials:}

The datasets used and/or analysed during the current study are available from the corresponding author on reasonable request. 


\section{Ethics approval and consent to participate:}

The study protocol has been approved by the Medical Ethics Committee of the Second Hospital of Lanzhou University, Lanzhou, Gansu, China.

\section{Consent to publish:}

Not applicable.

\section{Competing interests:}

The authors declare that they have no competing interests.

\section{References}

1. Babjuk, M.; Bohle, A.; Burger, M.; Capoun, O.; Cohen, D.; Comperat, E. M.; Hernandez, V.; Kaasinen, E.; Palou, J.; Roupret, M.; van Rhijn, B. W.; Shariat, S. F.; Soukup, V.; Sylvester, R. J.; Zigeuner, R., EAU Guidelines on Non-Muscle-invasive Urothelial Carcinoma of the Bladder: Update 2016. Eur Uro/ 2017, 71 (3), 447-461.

2. Chang, S. S.; Boorjian, S. A.; Chou, R.; Clark, P. E.; Daneshmand, S.; Konety, B. R.; Pruthi, R.; Quale, D. Z.; Ritch, C. R.; Seigne, J. D.; Skinner, E. C.; Smith, N. D.; McKiernan, J. M., Diagnosis and Treatment of Non-Muscle Invasive Bladder Cancer: AUA/SUO Guideline. J Uro/ 2016, 196 (4), 1021-9.

3. Sylvester, R. J.; van der Meijden, A. P.; Oosterlinck, W.; Witjes, J. A.; Bouffioux, C.; Denis, L.; Newling, D. W.; Kurth, K., Predicting recurrence and progression in individual patients with stage Ta T1 bladder cancer using EORTC risk tables: a combined analysis of 2596 patients from seven EORTC trials. Eur Urol 2006, 49 (3), 466-5; discussion 475-7.

4. Naselli, A.; Puppo, P., En Bloc Transurethral Resection of Bladder Tumors: A New Standard? J Endouro/ 2017, 31 (S1), S20-S24.

5. Kitamura, K.; Kataoka, K.; Fujioka, H.; Kashiwai, K., Transurethral resection of a bladder tumor by the use of a polypectomy snare. J Uro/ 1980, 124 (6), 808-9.

6. Sobin, TNM Classification of Malignant Tumours 7e. 2009.

7. Eble, J.; Sauter, G.; Epstein, J.; Sesterhenn, I.; Srigley, J.; Sesternenn, I.; Ebstein, J.; Ebele, J.; Sesterhann, I., Pathology and Genetics of Tumours of the Urinary System and Male Genital Organs. 2004.

8. Fritsche, H. M.; Otto, W.; Eder, F.; Hofstadter, F.; Denzinger, S.; Chaussy, C. G.; Stief, C.; Wieland, W. F.; Burger, M., Water-jet-aided transurethral dissection of urothelial carcinoma: a prospective clinical study. J Endourol 2011, 25 (10), 1599-603. 
9. Xishuang, S.; Deyong, Y.; Xiangyu, C.; Tao, J.; Quanlin, L.; Hongwei, G.; Jibin, Y.; Dongjun, W.; Zhongzhou, H.; Jianbo, W.; Lina, W.; Lin, Y., Comparing the safety and efficiency of conventional monopolar, plasmakinetic, and holmium laser transurethral resection of primary non-muscle invasive bladder cancer. J Endourol 2010, 24 (1), 69-73.

10. Zhang, K. Y.; Xing, J. C.; Li, W.; Wu, Z.; Chen, B.; Bai, D. Y., A novel transurethral resection technique for superficial bladder tumor: retrograde en bloc resection. World J Surg Oncol 2017, 15 (1), 125.

11. Xu, H.; Ma, J.; Chen, Z.; Yang, J.; Yuan, H.; Wang, T.; Liu, J.; Yang, W.; Ye, Z., Safety and Efficacy of En Bloc Transurethral Resection With 1.9 microm Vela Laser for Treatment of Non-Muscle-invasive Bladder Cancer. Urology 2018, 113, 246-250.

12. Balan, G. X.; Geavlete, P. A.; Georgescu, D. A.; Ene, C. V.; Bulai, C. A.; Paunescu, M. A.; Niculae, A.; Peride, I.; Lascar, I.; Neagu, T. P.; Geavlete, B. F., Bipolar en bloc tumor resection versus standard monopolar TURBT - which is the best way to go in non-invasive bladder cancer? Rom $\mathrm{J}$ Morphol Embryol 2018, 59 (3), 773-780.

13. Cheng, Y. Y.; Sun, Y.; Li, J.; Liang, L.; Zou, T. J.; Qu, W. X.; Jiang, Y. Z.; Ren, W.; Du, C.; Du, S. K.; Zhao, W. C., Transurethral endoscopic submucosal en bloc dissection for nonmuscle invasive bladder cancer: A comparison study of HybridKnife-assisted versus conventional dissection technique. J Cancer Res Ther 2018, 14 (7), 1606-1612.

14. Li, K.; Xu, Y.; Tan, M.; Xia, S.; Xu, Z.; Xu, D., A retrospective comparison of thulium laser en bloc resection of bladder tumor and plasmakinetic transurethral resection of bladder tumor in primary non-muscle invasive bladder cancer. Lasers Med Sci 2019, 34 (1), 85-92.

15. Yang, H.; Lin, J.; Gao, P.; He, Z.; Kuang, X.; Li, X.; Fu, H.; Du, D., Is the En Bloc Transurethral Resection More Effective than Conventional Transurethral Resection for Non-Muscle-Invasive Bladder Cancer? A Systematic Review and Meta-Analysis. Urol Int 2020, 1-8.

16. Avallone, M. A.; Sack, B. S.; El-Arabi, A.; Charles, D. K.; Herre, W. R.; Radtke, A. C.; Davis, C. M.; See, W. A., Ten-Year Review of Perioperative Complications After Transurethral Resection of Bladder Tumors: Analysis of Monopolar and Plasmakinetic Bipolar Cases. J Endourol 2017, 31 (8), 767-773.

17. Herr, H. W.; Donat, S. M., Quality control in transurethral resection of bladder tumours. BJU Int 2008, $102(9$ Pt B), 1242-6.

18. Cheng, B.; Qiu, X.; Li, H.; Yang, G., The safety and efficacy of front-firing green-light laser endoscopic en bloc photoselective vapo-enucleation of non-muscle-invasive bladder cancer. Ther Clin Risk Manag 2017, 13, 983-988.

19. Yuk, H. D.; Kim, J. K.; Jeong, C. W.; Kwak, C.; Kim, H. H.; Ku, J. H., Differences in Pathologic Results of Repeat Transurethral Resection of Bladder Tumor (TURBT) according to Institution Performing the Initial TURBT: Comparative Analyses between Referred and Nonreferred Group. BioMed research international 2018, 2018.

20. Hayashida, Y.; Miyata, Y.; Matsuo, T.; Ohba, K.; Sakai, H.; Taba, M.; Naito, S.; Taniguchi, K., A pilot study to assess the safety and usefulness of combined transurethral endoscopic mucosal resection and en-bloc resection for non-muscle invasive bladder cancer. BMC Urol 2019, 19 (1), 56. 
Figures

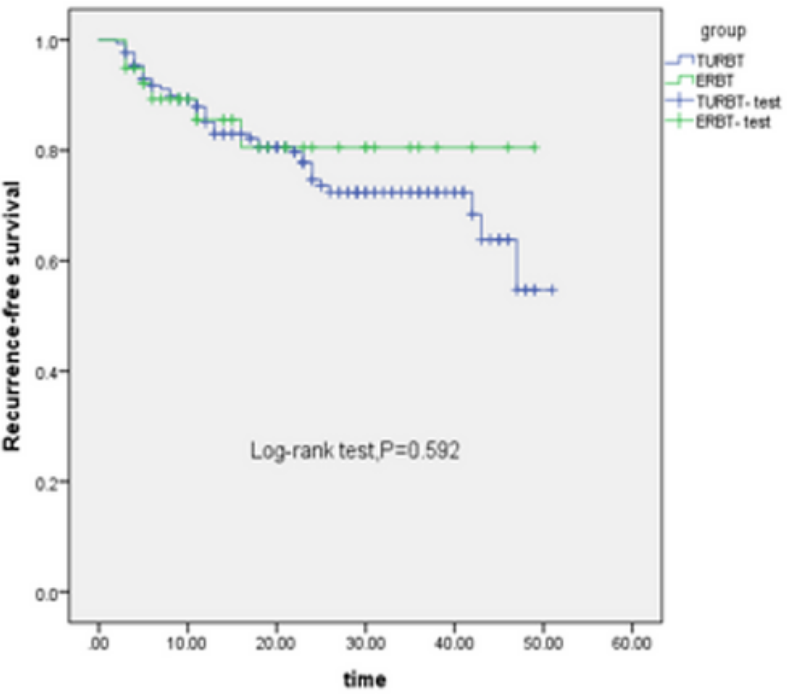

A.

\section{Figure 1}

Kaplan-Meier curve A. Kaplan-Meier curve before PSM; B. Kaplan-Meier curve after PSM

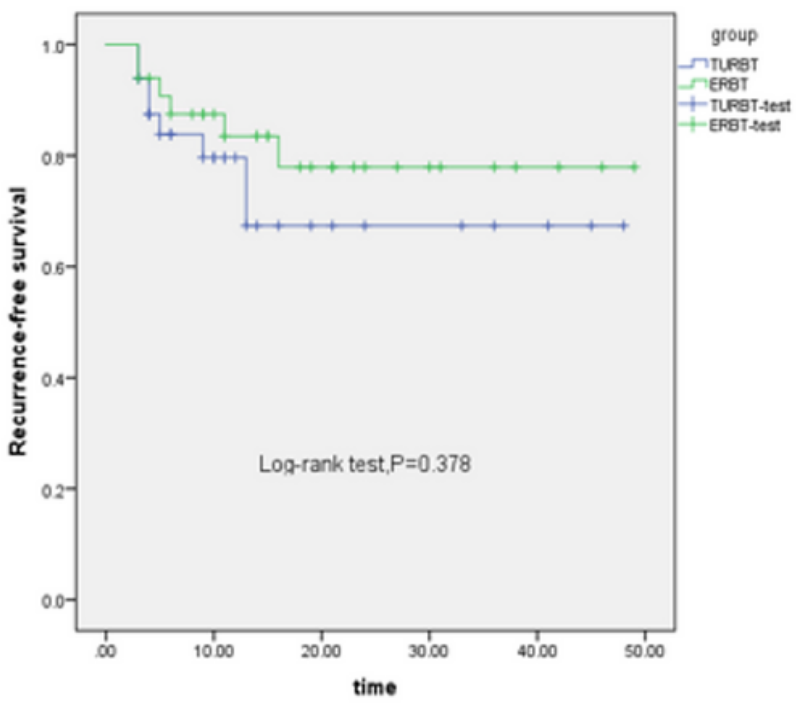

B. 